\title{
UXDs-Driven Transferring Method from TRIZ Solution to Domain Solution
}

\author{
Lihui $\mathrm{Ma}^{1,2}$, Guozhong $\mathrm{Cao}^{2}$, Yunxia Chang ${ }^{1}$, Zihui $\mathrm{Wei}^{2}$, and Kai Ma ${ }^{1}$ \\ ${ }^{1}$ School of Quality and Technical Supervision, Hebei University, Baoding 071002, China \\ ${ }^{2}$ Institute of Design for Innovation, Hebei University of Technology, Tianjin 300130, China \\ \{Lihui Ma, Guozhong Cao, Yun-xia Chang, Zihui Wei, \\ Kai Ma, malh198\} @yahoo.com.cn
}

\begin{abstract}
The translation process from TRIZ solutions to domain solutions is an analogy-based process. TRIZ solutions, such as 40 inventive principles and the related cases, are medium-solutions for domain problems. Unexpected discoveries (UXDs) are the key factors to trigger designers to generate new ideas for domain solutions. The Algorithm of UXD resolving based on MeansEnds Analysis(MEA) is studied and an UXDs-driven transferring method from TRIZ solution to domain solution is formed. A case study shows the application of the process.
\end{abstract}

Keywords: UXD, TRIZ solution, domain solution, transferring method, MEA.

\section{Introduction}

TRIZ (Theory of Inventive Problem Solving) is developed by analyzing and inducing a great deal of patents within the world database. TRIZ has put forward the concepts, models and tools of inventive problem solving. But the TRIZ solutions, such as inventive principles, are not domain solutions needed by designers. How to translate the TRIZ solutions into domain solutions still remains a problem when TRIZ is applied.

The translation process is an analogy-based process. Unexpected discoveries (UXDs) are the key factors to trigger designers to generate new ideas for domain solutions during this process. How to find UXDs from the TRIZ special solutions and design cases is becoming an important step for the domain solutions [1-2].

The contradiction solving method is the most important method in TRIZ. This study will be restricted to find solutions for this kind of inventive problems. The discovery process of UXDs from the TRIZ solutions will be studied. And an UXDs-driven transferring method from TRIZ solution to domain solution process will be formed.

\section{UXDs in Conceptual Design}

Suwa and Gero have produced a concept so called "situated-invention (S-invention)" [3], which means a designer has generated the issue or requirement for the first time in the current design task in a way situated in the design setting. Fig. 1 shows that the Inventive Problem Solving process in TRIZ is a kind of S-invention, in which the sources are shown in the CAIs(Computer-aided innovation systems) world. 
In TRIZ world the contradiction is first to be transformed to a standard contradiction using 39 engineering parameters in TRIZ and then four or less inventive principles are selected through the matrix. Also, some design cases following the principles are contained. The principles selected and the cases with these principles are TRIZ solutions.

In CAIs, a case is described using a sketch with text to explain the working principle of that sketch. When one principle as a TRIZ solution is selected all the cases relevant to that can be browsed one by one. New ideas for the domain solutions may be formed from designers' mind during the browsing process. Fig. 1 shows the model of design situation for this specific environment.

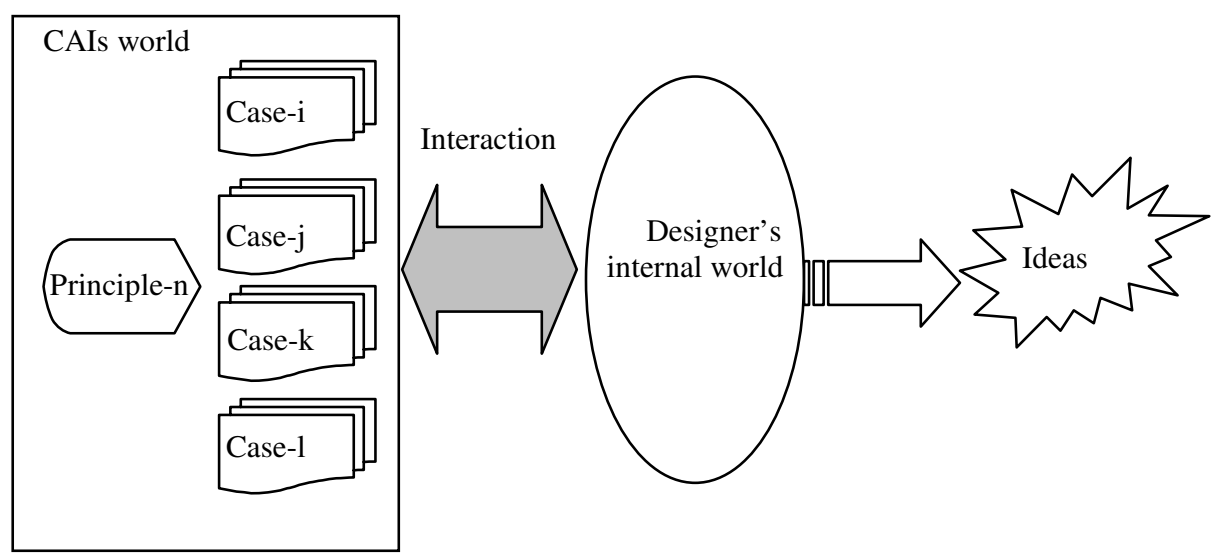

Fig. 1. Design situation using CAIs for technical contradiction solving

In the designer's internal world, the selected principles and cases as codified knowledge are apperceived, and some cues are found, which are triggers for designers to produce domain solutions. So in the situation shown in Fig. 1, the creative ability for designers should be increased.

Gero et al have studied the generation of S-invention, and summarized a design process [4-7]. First, the agents, such as designers or intelligent software, apperceive the domain problem and determine source design and goal design. Then agents find unexpected discoveries (UXDs) through the matching of source design and goal design. UXDs are transferred to goal design by mapping, and new goal is generated. Then modified goal design is produced. There may be multi-source designs, and the last modified goal design is the concept of solving domain problems through modifying goal design continually.

Gero and his group are major in architectural design. So the source designs are drawings of different kinds of architectures. If the source designs are substituted by TRIZ solutions and the cases corresponding to them the design process for generation of S-invention can be applied to generate the domain solutions. Designers find several UXDs and modify goal design depending on their design experience, the comprehension of domain problems and the situation. At last some modified goal designs are domain solutions. This process shown in Fig. 2 is an analogy reproduction process of source design in goal design by UXDs, which can be named UXD reproduction. 


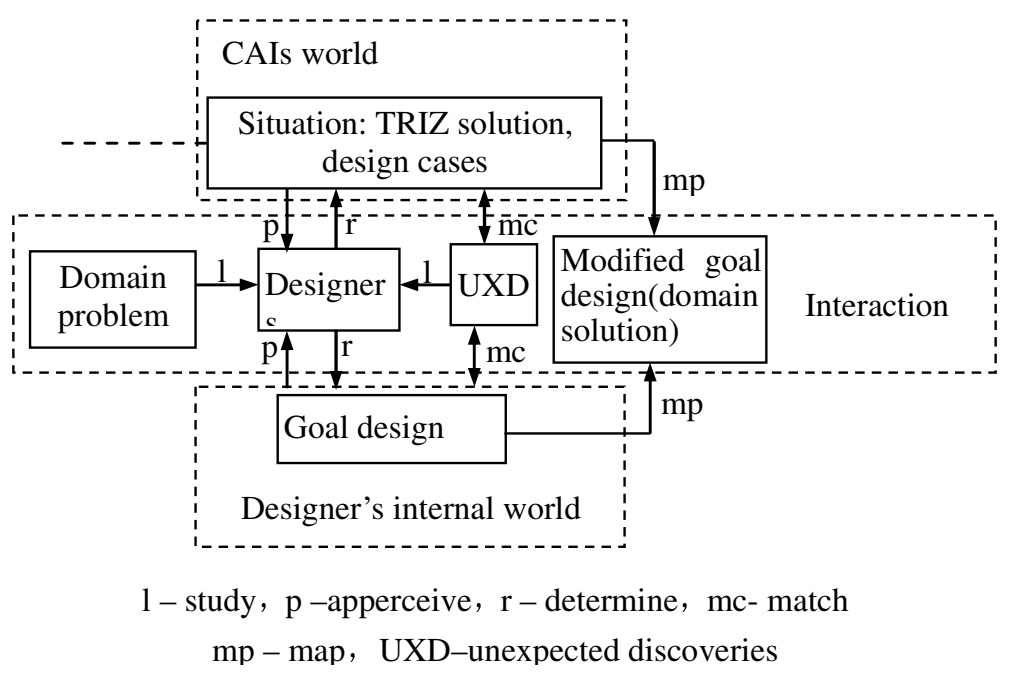

Fig. 2. Analogy reproduction process of source design by UXD

The key for the analogy process is how ideas of solving domain problems appear from the designers, which is related to constructive memory of cognitive science [8].

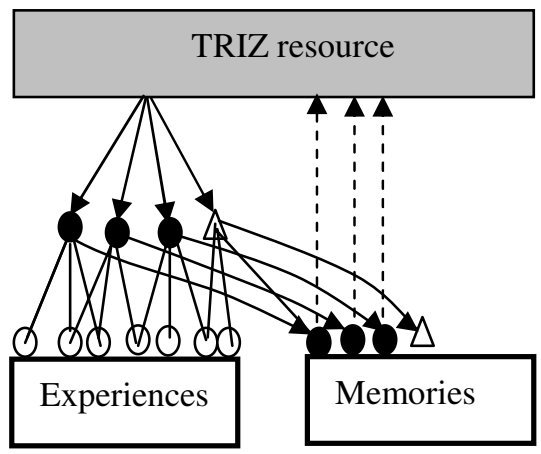

Former experiences

Memory produced by the action of former experiences and situation together, which is also as experience when new memory is produced.

$\triangle$ The new memory produced by action of situation and experience

Fig. 3. The principle of constructive memory

According to the concept of constructive memory, the memory is not direct reappearance of former experience but a function of former experience, changes after producing these experience and situation of memory requirement. A simplified principle of constructive memory is shown in Fig. 3. 
In the Fig. 2, UXDs enlighten designers on invention and make new concepts appear, so discovering and transferring UXDs are the key for the success generation of domain solution. Experiences and UXDs drive agents to generate new concepts or ideas according to the process of Fig. 3. The new concepts are mapped to the goal design to produce a new goal design.

\section{UXDs-Driven Generation Process of Domain Solution}

For UXDs more operational, the algorithm of Means-Ends Analysis (Means-Ends Analysis: MEA) [9] is introduced to the process of UXD reproduction.

MEA is an artificial intelligence (AI) technique for problem solving which is based on detecting differences between states and then trying to reduce those differences. MEA uses both forward and backward reasoning and a recursive algorithm to systematically minimize the differences between the initial and the goal states.

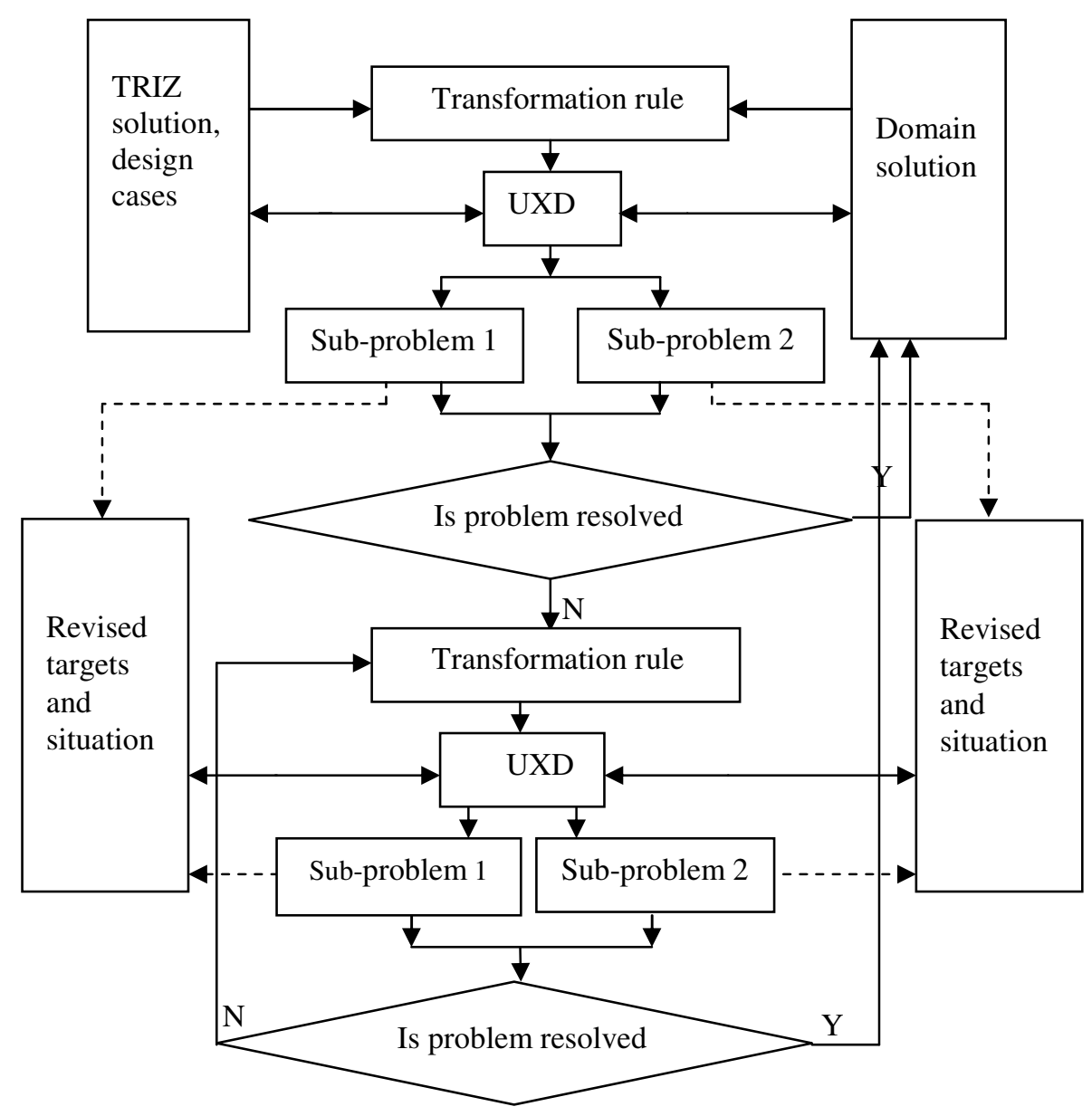

Fig. 4. UXD reproduction based on MEA 
The reproduction process of UXD based on MEA was shown in Fig. 4.The Algorithm of UXD resolving based on MEA is shown as below:

1) Compare the current state and target state, if states are identical then return success;

2 ) Select the most important difference and reduce it by the appropriate transformation rule, which is the invenve principles of TRIZ;

3 ) According to the Design situation, find unexpected discoveries (UXDs) through physical action. UXDs are the specific operators here.

4) If the UXD can make the transformation succeed, reproduction is completed. Otherwise, it will be divided into two possible sub-problems:

If the current state can not apply this transformation, then set up a First part from the current state to the required state; If this transformation result can not get precise goal state, then set up a Last part from the result state to the goal state. Therefore the design goals are modified;

5) The above two sub-problems are easy to solve compare to the original problem if the selected division is suitable. Therefore the ultimate goal design can be obtained;

6) If the sub-problems can not be solved, reapeat the recursive MEA algorithm until each sub-problem can be solved.

It is noteworthy that, after the problem is divided into sub-problems, design situation will have corresponding changes. Sub-problems will constitute brand-new design situation and induce new UXDs, then produce lower grade sub-problems.

\section{Case Study}

For the viscous nature of traditional Chinese medicine, dropping pill machine for traditional Chinese medicine is easy to have the droppers block during dropping process. It will increase the complexity of the dropper shape to improve this status. Thus a design contradiction is formed between the above two factors, which can be transformed to a standard contradiction using 39 engineering parameters in TRIZ. TRIZ solution for the design contradiction above is shown in Table 1.

The dropper aperture should be increased using "parameter changes" and " Partial or Excessive Actions ". But in order to guarantee the corresponding diameter of dropping pills, the aperture can not be enlarged unlimitedly. This is not the fundamental solution to the contradiction; " Segmentation " can not be applied here; " Beforehand Cushioning " means "prepares the safe/remedial measure in advance", which may be considered as TRIZ specia solution.

Table 1. TRIZ solution of contradiction induced by dropper blocking

\begin{tabular}{cccc}
\hline $\begin{array}{c}\text { Improvement } \\
\text { factors }\end{array}$ & $\begin{array}{c}\text { Deterioration } \\
\text { factors }\end{array}$ & TRIZ solution (inventive principles) \\
\hline 27 Reliability & 12 Shape & $\begin{array}{l}35 \text { parameter changes, 1 segmentation, } \\
16 \text { partial or excessive Actions, 11 } \\
\text { beforehand cushioning }\end{array}$ \\
\hline
\end{tabular}


Table 2 is the corresponding cases for " Beforehand Cushioning " through CAI soft InventionTool 2.0 [10].

Table 2. Corresponding cases of " Beforehand cushioning " in InventionTool 2.0

\begin{tabular}{|c|c|c|c|}
\hline No. & Case & Case sketch & Case description \\
\hline 1 & Airbag & & $\begin{array}{l}\text { If the collision happened in the front, } \\
\text { seat belt can protect the driver. } \\
\text { However, it is invalid on the side } \\
\text { collision. Recommend to adopt side } \\
\text { airbag, which is placed on the back of } \\
\text { seat. When the side collision happening, } \\
\text { the airbag will expand to make injury } \\
\text { avoided. }\end{array}$ \\
\hline 2 & $\begin{array}{l}\text { Glass jars } \\
\text { positionin } \\
\text { g device }\end{array}$ & (0) (2) (C) & $\begin{array}{l}\text { Glass jars are easy to damage during } \\
\text { transportation. Propose to configure } \\
\text { glass jars positioning device in the } \\
\text { packing case using Beforehand } \\
\text { cushioning. It includes pallet with } \\
\text { positioning grooves and top plate with } \\
\text { restricting holes. And their centers of } \\
\text { circle are in the same axis. So Glass jars } \\
\text { collision and label friction can be } \\
\text { effectively avoided. }\end{array}$ \\
\hline
\end{tabular}

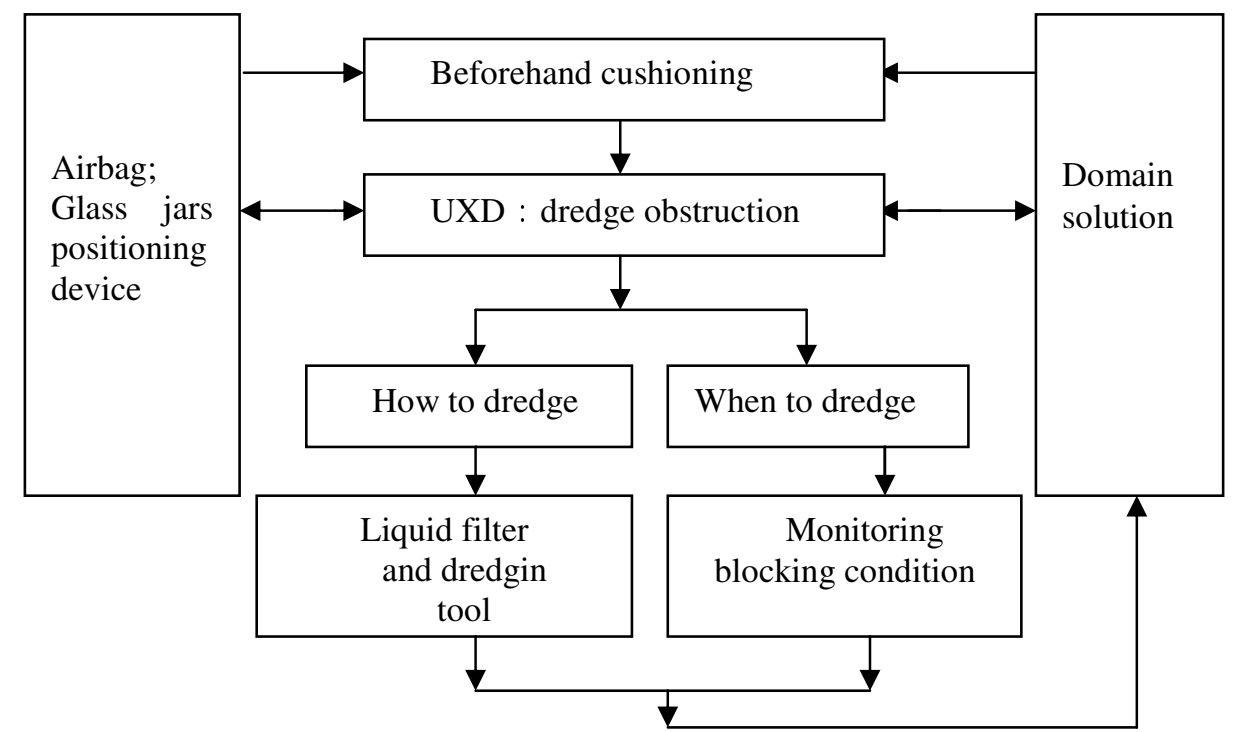

Fig. 5. UXD reproduction process for the contradiction induced by dropper blocking 
The design situation has been constituted by the examples in Table 2. Fig. 5 is UXD reproduction process aimed at the contradiction of dropper blocking based on MEA.

In Fig. 5, TRIZ solution transferring process is divided into two sub-problems by UXD: One from the current state to the transformation required state, i.e. how to dredge; the other from the result state to the goal state, i.e. when to dredge.UXD reproduction can be achieved by solving the two sub-problems.

Fig. 6 shows the domain solution corresponding to the contradiction induced by dr opper blocking. Its principle is to monitor the blocking situation of dropper through photoelectric sensor and inform the needle-type switch to dredge timely.

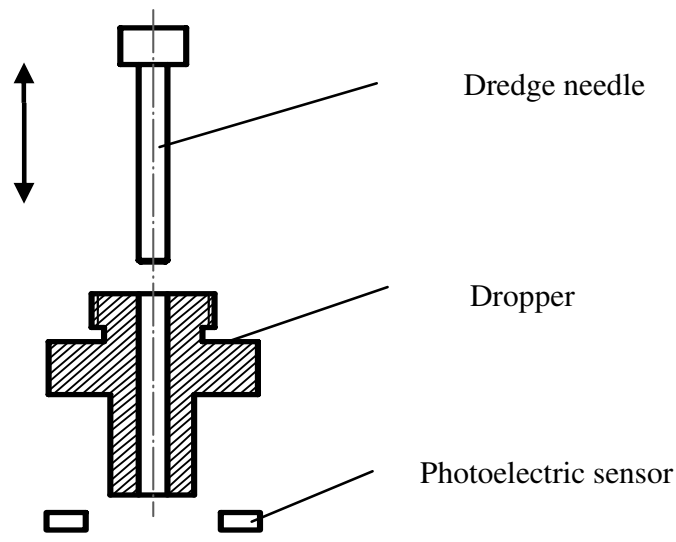

Fig. 6. Domain solution corresponding to the contradiction induced by dropper blocking

\section{Conclusion}

The translation process from TRIZ solutions to domain solutions is an analogy-based process. The application of the TRIZ resources will improve the validity of analogybased design.

To find UXDs from the design sources are key step for generate successful domain solution for innovation.

A six step process model based on MEA is formed for TRIZ solution translation related to inventive principles of TRIZ, in which UXDs is driving force for generating new domain solution. TRIZ solution transferring process is divided into two subproblems by UXD: One is from the current state to the transformation required state; The other one is from the result state to the goal state. UXD reproduction can be achieved by resolving the two sub-problems.

The generation of an improved concept of dropping pill machine components for traditional Chinese medicine shows the process model step-by-step.

\section{Acknowledgments}

This research is supported in part by the Natural Science Foundation of Hebei under Grant Numbers E2008000101, the Key Project of the Ministry of Science and 
Technology of the People's Republic of China under Grant Numbers 2008IM030100. Any opinions or findings of this work are the responsibility of the authors, and do not necessarily reflect the views of the sponsors or collaborators.

\section{References}

1. Tan, R.H.: Process Of Two Stages Analogy-based Design Employing TRIZ[A]. In: 1st IFIP TC-5 Working Conference on CAI[C], ULM, Germany, November 14-15, pp. 59-68 (2005)

2. Tan, R.H., Zhang, R.H., Liu, F., et al.: Two stages analogy-based conceptual design based on TRIZ. Computer Integrated Manufacturing Systems 12(3), 328-331 (2006) (in Chinese)

3. Suwa, M., Gero, J.S., Purcell, T.: Unexpected discoveries and S-inventions of design requirements. Design Studies 21(6), 539-567 (2000)

4. Gero, J.S.: Concept formation in design: towards a loosely wired brain model. In: Candy, L., Hori, K. (eds.) Strategic Knowledge and Concept Formation Workshop, pp. 135-146. Loughborough University of Technology, Loughborough (1997)

5. Kulinski, J., Gero, J.S.: Constructive representation in situated analogy in design. In: Vries, B., Achten, H. (eds.) CAADFutures 2001, pp. 507-520. Kluwer, Dordrecht (2001)

6. Ricardo, S., Gero, J.S.: Computational models of creative situations. In: Gero, J.S., Brazier, F.M.T. (eds.) Agents in Design 2002 Key Centre of Design Computing and Cognition, University of Sydney, pp. 165-180 (2002)

7. Gero, J.S.: Design tools as situated agents that adapt to their use. In: Dokonal, W., Hirschberg, U. (eds.) eCAADe21, eCAADe, Graz University of Technology, pp. 177-180 (2003)

8. Gero, J.S.: Constructive memory in design thinking. In: Goldschmidt, G., Porter, W. (eds.) Design Thinking Research Symposium: Design Representation, pp. 29-35. MIT, Cambridge (1999)

9. Li, C.: Artificial Intelligence and Application[M], pp. 207-211. China Machine Press, Beijing (2006)

10. Computer aided inventive problem solving system: InventionTool2.0. Chinese patent of software[Z]. 2003SR9983 (2003) (in Chinese) 